\title{
A study on template effects using irregular porous isotactic poly(methyl methacrylate) films constructed with syndiotactic rich poly(methacrylic acid) and isotactic poly(methyl methacrylate)
}

\begin{abstract}
Masumi Maegawa ${ }^{1}$, Hiroharu Ajiro ${ }^{1,2}$, Daisuke Kamei ${ }^{1}$ and Mitsuru Akashi ${ }^{1,2}$
To investigate the stereocomplex formation efficiency with various syndiotactic-poly(methacrylic acids) (st-PMAAs) after the extraction of the syndiotactic-rich PMAA from stereocomplex film, the low syndiotacticity of PMAA $(r r=78 \%)$ was used to prepare irregular isotactic poly(methyl methacrylate) (it-PMMA)/st-PMAA $(r r=78 \%)$ stereocomplex thin films on substrates. The resultant irregular porous it-PMMA thin films showed effective incorporation of st-PMAA ( $r r=78$ and $96 \%$ ), suggesting a structural rearrangement of the it-PMMA main chain. However, the template polymerization in porous it-PMMA thin films with a monomer of methacrylic acid resulted in a stereoregular replica of the st-PMAA, without any rearrangement of the it-PMMA. When irregular stereocomplex formation was employed, these results demonstrated a clear difference between polymer-polymer interactions and polymer-monomer interactions and indicated that a high stereoregularity was necessary to achieve strict control of the stereoregular template polymerization on the porous thin film.
\end{abstract}

Polymer Journal (2013) 45, 898-903; doi:10.1038/pj.2012.236; published online 27 February 2013

Keywords: incorporation; layer-by-layer assembly; poly(methyl methacrylate); porous thin film; stereocomplex; tacticity

\section{INTRODUCTION}

Template polymerization is a controlled polymerization method that uses a monomer in the presence of an interactive template polymer to control the rate of synthesis of the polymer structure. ${ }^{1,2}$ This method has been studied for many decades, primarily to improve the reaction rate. For example, decades ago, Połowiński $\mathrm{i}^{3,4}$ and Takemoto ${ }^{5-8}$ reported that the reaction rate had been improved by utilizing a hydrogen bond as the driving force. Sleiman and coworkers successfully polymerized bulky monomers, which had not been polymerized until then, by taking advantage of the hydrogen bonds of the base pairs. ${ }^{9}$ Furthermore, Sawamoto and coworkers achieved monomer selective polymerization through electrostatic interactions by adding an initiator to the polymer template. ${ }^{10}$ These studies utilized strong interactions between the template polymer and these monomers. Molecular design-based studies can be expected if the polymerization mechanism can be clarified. However, studies have also been performed that used weak interactions (Van der Waals). Recently, Kadokawa and colleagues ${ }^{11}$ reported the polymerization of the helical complex of amylase and poly(glycolic acid-co- $\varepsilon_{-}^{-}$ caprolacton), such that the complex structure has a key conformation. This method of polymerization using complex formations has received much attention. However, the precise control of polymer structures using the template approach has been challenging.
We have focused on stereoregular poly(methyl methacrylate)s (PMMAs), which form stereocomplexes by Van der Waals forces resulting in weak polymer-polymer interactions. ${ }^{12,13}$ This complex is composed of a helical structure that is formed from an isotactic (it-) polymer and a syndiotactic (st-) polymer, which recognize one another's molecular structure. ${ }^{14-16}$ The issue of how to achieve template polymerization with a stereocomplex conformation as the driving force has also been investigated. Challa and coworkers as well as other researchers have found a significant difference in reaction rate and stereoregularity, ${ }^{17-26}$ but strict control of the polymer structure was not achieved in the solution state. However, we investigated porous thin films on a substrate, which were prepared by layer-bylayer (LbL) assembly using it-PMMA and st-poly(methacrylic acid) (st-PMAA), ${ }^{27-30}$ and the subsequent extraction of one component through differential solubility. Surprisingly, we found that the porous film functions as an effective template for the polymerization system. $^{31-34}$ This technique gave strict control of the polymethacrylate structure, including a high stereoregularity and a low molecular weight distribution (polydispersity: PDI), measured by the radical method.

Recently, we focused on the template polymerization mechanism and a structural analysis of the porous film as a template field. As a comparison, we also investigated a suspension of crosslinked

${ }^{1}$ Department of Applied Chemistry, Graduate School of Engineering, Osaka University, Suita, Japan and ${ }^{2}$ The Center for Advanced Medical Engineering and Informatics, Osaka University, Suita, Japan

Correspondence: Dr M Akashi, Department of Applied Chemistry, Graduate School of Engineering, Osaka University, 2-1 Yamada-oka, Suita, Osaka 565-0871, Japan. E-mail: akashi@chem.eng.osaka-u.ac.jp

Received 23 October 2012; revised 25 November 2012; accepted 27 November 2012; published online 27 February 2013 
stereocomplexes without any substrate. ${ }^{35}$ We reported that the molecular recognition capability of the porous thin film on a substrate was higher than the crosslinked polymer. Therefore, it is necessary to collect more detailed information on the template polymerization system, an LbL film on a substrate.

In this study, we used syndiotactic-rich PMAA ( $r r$ triad $=73$ and $78 \%$ ) and $i$-PMMA ( $m m$ triad $=95$ and 99\%) for the stereocomplex formation of porous it-PMMA thin films, and methacrylic acid (MAA) was polymerized with the template polymerization approach. We examined the effects of irregularity of the template and low stereoregularity, and the template polymerization mechanism is discussed.

\section{MATERIALS AND METHODS}

Materials

it-PMMA ${ }^{36}$ and st-PMAA ${ }^{37}$ were synthesized by conventional anionic polymerization (Table 1). The average molecular weights and distributions were measured by size exclusion chromatography using PMMA standards with a tetrahydrofuran eluant at $40{ }^{\circ} \mathrm{C}$ and a flow rate of $0.6 \mathrm{mlmin}^{-1}$. The tacticities were determined from the $\alpha$-methyl proton signal using $400 \mathrm{MHz}$ NMR (nitrobenzene- $d_{5}, 110^{\circ} \mathrm{C}$ ). The characterization of st-PMAA was achieved after the carboxyl group was methylated. Acetonitrile, MAA, sodium hydroxide solution $(\mathrm{NaOH}$ aq.) and radical initiator VA-044 (2,2' -azobis[2-(2imidazolin-2-yl)propane]dihydrochloride) were purchased from Wako Pure Chemical Industries (Kanagawa, Japan). Ultrapure distilled water was provided by the Milli-Q laboratory system (Darmstadt, Germany).

\section{Film preparation and incorporation of st-PMAA}

An AT-cut quartz crystal microbalance (QCM) with a parent frequency of $9 \mathrm{MHz}$ was obtained from USI (Fukuoka, Japan) and employed as the substrate. The frequency was monitored by an Universal Counter (Model 53131A, Hewlett-Packard Japan, Tokyo, Japan). The quartz crystal $(9 \mathrm{~mm}$ diameter) was coated on both sides with mirror-like polished gold electrodes $(4.5 \mathrm{~mm}$ in diameter). First, the QCM electrode was cleaned with a piranha solution, a mixed aqueous solution of $98 \% \mathrm{H}_{2} \mathrm{SO}_{4} / 40 \% \mathrm{H}_{2} \mathrm{O}_{2}(3 / 1, \mathrm{v} / \mathrm{v})$ for 3 min, followed by rinsing with ultrapure water and drying with $\mathrm{N}_{2}$ gas. ${ }^{38}$ The LbL films were prepared as follows: the substrate was alternatively immersed in an it-PMMA acetonitrile solution and an st-PMAA acetonitrile/water $(4 / 6, \mathrm{v} / \mathrm{v})$ solution at a concentration of 0.017 unitM for $5 \mathrm{~min}$ at $25^{\circ} \mathrm{C}$ each. The substrate was rinsed with each solvent and dried with $\mathrm{N}_{2}$ gas whenever taken out of each solution. This alternative deposition step was repeated 16 times to fabricate the stereocomplex of $i t-\mathrm{PMMA} /$ st-PMAA on the substrate. Porous itPMMA thin films were prepared by immersion into a $10 \mathrm{~mm} \mathrm{NaOH}$ aqueous solution for $10 \mathrm{~min}$ and washed with ultrapure water. ${ }^{28,29,32}$

\section{Incorporation of st-PMAA into it-PMMA porous film}

Porous it-PMMA thin films were immersed into an st-PMAA acetonitrile/ water $(4 / 6, \mathrm{v} / \mathrm{v})$ solution at a concentration of 0.017 unitM at $25^{\circ} \mathrm{C}$. Total

Table 1 Material polymer in this study ${ }^{\mathrm{a}}$

\begin{tabular}{lccc}
\hline $\begin{array}{l}\text { Polymer } \\
\text { name }\end{array}$ & $\begin{array}{c}\text { Tacticity } \\
\text { mm:mr:rr }\end{array}$ & $M_{n}^{\mathrm{c}}$ & \\
\hline it-PMMA-1 & $95: 4: 1$ & 14700 & 1.50 \\
it-PMMA-2 & $99: 1: 0$ & 52700 & 1.42 \\
st-PMAA-1 & $3: 24: 73$ & 18200 & 2.20 \\
st-PMAA-2 & $3: 24: 73$ & 50400 & 2.20 \\
st-PMAA-3 & $1: 21: 78$ & 60800 & 1.41 \\
st-PMAA-4 & $1: 3: 96$ & 15200 & 1.71 \\
\hline
\end{tabular}

Abbreviations: it-PMMA, isotactic-poly(methyl methacrylate); st-PMAA, syndiotacticpoly(methacrylic acid).

${ }^{a}$ st-PMAA were synthesized by anion polymerization and analyzed after methylation with diazomethane.

diazomethane. ${ }^{1}$ Determined by ${ }^{1} \mathrm{H}$ NMR spectra in nitrobenzene- $d_{5}$ at $110^{\circ} \mathrm{C}(400 \mathrm{MHz})$.

cDetermined by size exclusion chromatography (SEC) with PMMA standard in tetrahydrofuran 'Determined by size
(THF) at $40^{\circ} \mathrm{C}$. immersion time was $2 \mathrm{~h}$. The substrate was rinsed with each solvent, and dried with $\mathrm{N}_{2}$ gas whenever it was removed from the solution.

\section{Template polymerization on QCM substrate}

Distilled MAA was dissolved in ultrapure water to prepare a $35 \mathrm{~mm}$ monomer solution, and the porous it-PMMA thin films on the QCM substrate were added to the solution. ${ }^{32-34}$ Dry nitrogen gas was handled at room temperature for more than $15 \mathrm{~min}$ before use. Then, VA-044 was added under nitrogen atmosphere and heated to $40^{\circ} \mathrm{C}$ for $2 \mathrm{~h}([I] /[M]=1 / 20)$. After polymerization, the porous it-PMMA thin film was washed with ultrapure water, and the frequency shift and Fourier transform infrared spectroscopy (FT-IR) of the porous it-PMMA thin film were measured.

\section{Template polymerization on silica gel}

To prepare porous it-PMMA thin films, silica gel $(2 \mathrm{~g}$, mean diameter $7 \mu \mathrm{m})$ was alternatively immersed into an it-PMMA acetonitrile solution and an stPMAA acetonitrile/water $(4 / 6, \mathrm{v} / \mathrm{v})$ solution at a concentration of 0.017 unitM for $5 \mathrm{~min}$ at $25^{\circ} \mathrm{C}$ each. ${ }^{32-34}$ The substrate was rinsed with each solvent, whenever it was taken out from each solution. This alternative deposition step was repeated 100 times $(50$ cycles) to fabricate the stereocomplex of it-PMMA/ st-PMAA on the substrate. Porous it-PMMA thin films were prepared by immersing stereocomplex films into a $35 \mathrm{ml} \mathrm{NaOH}$ aqueous solution (10 $\mathrm{mM}$ ) three times. Next, $0.3 \mathrm{ml}$ of MAA was dissolved in $100 \mathrm{ml}$ ultrapure water, and the porous it-PMMA thin films on silica gel were added to the solution. Dry nitrogen gas was handled for more than 15 min before use, and then VA-044 $\left(57 \mathrm{mg}\right.$ ) was added under nitrogen atmosphere and heated to $40^{\circ} \mathrm{C}$ for $2 \mathrm{~h}$. Afterwards, the mixture was vented and cooled down to $0{ }^{\circ} \mathrm{C}$ to stop the reaction. The silica gel was washed with water to recover recrementitious PMAA, which was produced in solution. Then PMAA, which was synthesized in porous it-PMMA thin film, was extracted using $10 \mathrm{~mm} \mathrm{NaOH} a q$. The silica gel with the porous it-PMMA thin films was used three times as the template.

\section{Quartz crystal microbalance}

The frequency was monitored by a frequency counter (Model 53131A) and was recorded manually. The QCM leads were sealed and protected with a rubber gel to prevent degradation from the solvent during immersion in the organic solutions and in the heated water. The amount of adsorbed polymers, $\Delta m$, could be calculated by measuring the frequency decreases in the QCM, $\Delta F$ using Sauerbrey's ${ }^{39}$ Equation (1)

$$
\left.\Delta F=2 F_{0}^{2} /\left(A \rho_{\mathrm{q}} \mu_{\mathrm{q}}\right)^{1 / 2}\right) \times \Delta m
$$

where $F_{0}$ is the parent frequency of the QCM $(9 \mathrm{MHz}), A$ is the electrode area $\left(0.159 \mathrm{~cm}^{2}\right), \rho_{\mathrm{q}}$ is the density of the quartz $\left(2.5 \mathrm{~g} \mathrm{~cm}^{-3}\right)$, and $\mu_{\mathrm{q}}$ is the shear modulus $\left(2.95 \times 10^{11} \mathrm{dyn}^{-2}\right)$. This equation was reliable when measurements were taken in air, as described in this study, because the solvent mass is never detected as a frequency shift, and the effect of the viscosity of the absorbent on the frequency can be ignored.

\section{Infrared spectroscopy}

The LbL assembled thin films of it-PMMA and st-PMAA were prepared on QCM substrates or silica gels. Attenuated total reflection IR spectra of the thin films were then obtained with a Spectrum 100 FT-IR spectrometer (PerkinElmer, Waltham, MA, USA). The interferograms were co-added eight times and Fourier transformed at a resolution of $4 \mathrm{~cm}^{-1}$.

\section{RESULTS AND DISCUSSION}

We employed QCM analysis to calculate the amount of the stereocomplex film and the porous it-PMMA thin film assembled onto a gold substrate, and the amount of st-PMAA incorporated into porous it-PMMA thin films by Sauerbrey's equation. ${ }^{38,39}$ A typical QCM analysis is shown in Figure 1. The stepwise stereocomplex assembly of it-PMMA/st-PMAA and the selective extraction of st-PMAA from the assembled films was confirmed in previous studies. ${ }^{28-35,40}$ To confirm the preparation of porous films, another experiment 


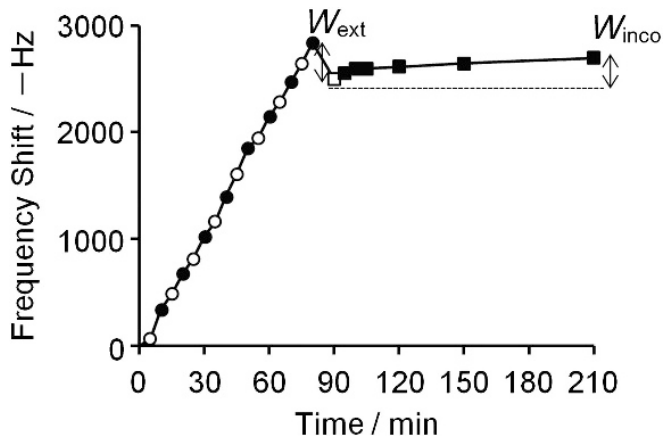

Figure 1 Typical figure of quartz crystal microbalance (QCM) analysis of stepwise assembly from an isotactic-poly(methyl methacrylate) 2 (it-PMMA-2) $(m m=99 \%)$ acetonitrile solution (white circle) and a syndiotactic-poly(methacrylic acid) 3 (st-PMAA-3) ( $r r=78 \%$ ) solution of mixed acetonitrile/water (4/6, v/v) solvent (black circle), extraction of st-PMAA with $10 \mathrm{~mm} \mathrm{NaOH}$ aq. (white square), and incorporation with porous it-PMMA film into st-PMAA-3 $(r r=78 \%)$ solution of mixed acetonitrile/water $(4 / 6, \mathrm{v} / \mathrm{v})$ solvent (black square).

Table 2 Results of complex efficiency (CE)

\begin{tabular}{|c|c|c|c|c|}
\hline Run & Polymer & $\begin{array}{l}\text { Tacticitya } \\
\text { mm:mr:rr }\end{array}$ & $M_{n}^{\mathrm{b}}$ & $C E(\%)$ \\
\hline 1 & st-PMAA-1 & $3: 24: 73$ & 18200 & $66 \pm 20$ \\
\hline 2 & st-PMAA-3 & $1: 21: 78$ & 60800 & $91 \pm 39$ \\
\hline 3 & $s t-P M A A-4$ & $1: 3: 96$ & 15200 & $>100$ \\
\hline
\end{tabular}

Abbreviation: st-PMAA, syndiotactic-poly(methacrylic acid).

a Determined by ${ }^{1} \mathrm{H}$ NMR spectra in nitrobenzene- $d_{5}$ at $110^{\circ} \mathrm{C}(400 \mathrm{MHz})$.

betermined by SEC with PMMA standard in tetrahydrofuran (THF) at $40^{\circ} \mathrm{C}$

was carried out and this result suggested that the extraction of st-PMAA from the assembled films was achieved within $10 \mathrm{~min}$ (see Supplementary Information; Supplementary Figure S1).

The incorporation capability was estimated using the complex efficiency (CE), which is defined as

$$
\mathrm{CE}(\%)=\left(W_{\text {inco }} / W_{\text {ext }}\right) \times 100
$$

where $W_{\text {inco }}$ is the increased weight in the incorporation stages and $W_{\text {ext }}$ is the decreased weight in the st-PMAA extraction stages.

Unlike previous reports, the amount of st-PMAA extracted at the $\mathrm{NaOH}$ aq. step was very low, most likely because it was difficult to form perfect stereocomplex pairs due to the low stereoregularity of the $s t$-PMAA at the LbL assembly steps and because the st-PMAA-3 $(r r=78 \%)$ might be rinsed away at each it-PMMA-2 assembly step. The small amount of extracted st-PMAA suggests that an excess amount of it-PMMA was present on the substrate. When the same stereoregularity, st-PMAA-3 $(r r=78 \%)$, was incorporated after the extraction, the CE had reasonable values of $91 \pm 39 \%(n=4)$ (Table 2, Run 2). Thus, this film has nanoporous functionality within a large margin of error, fitting in with the syndiotactic-rich $(r r=78 \%)$ stereoregularity. This result suggested that the molecules were not aligned in order and this porous it-PMMA thin film was unsound. This outcome most likely occurred because stereocomplex formation with the it-PMMA $(m m>90 \%)$ and the st-PMAA $(r r<90 \%)$ was only partially achieved.

Next, to investigate more functions of this porous film, other stPMAAs with different tacticities and molecular weights were incorporated into 'irregular' porous it-PMMA films. Because a previous

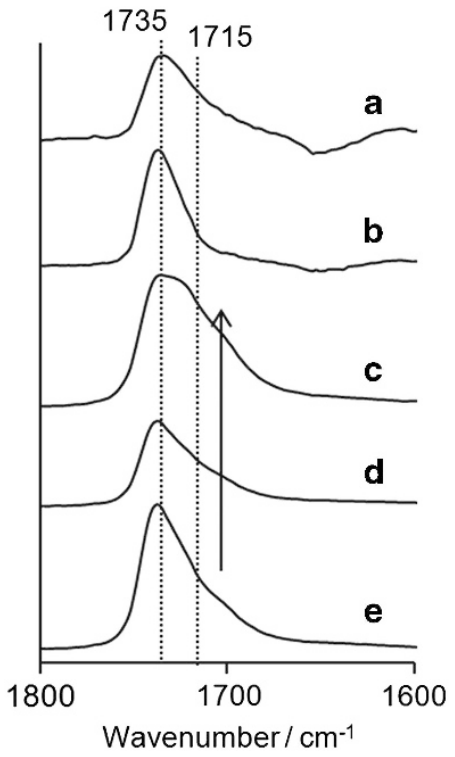

Figure 2 FT-IR/attenuated total reflection (ATR) spectra of stereocomplex film (a), porous isotactic-poly(methyl methacrylate) (it-PMMA) film (b), incorporated with syndiotactic-poly(methacrylic acid) 4 (st-PMAA-4) $(r r=96 \%) \quad$ (c), incorporated with st-PMAA-3 ( $r r=78 \%) \quad(d)$, and incorporated with st-PMAA-1 ( $r r=73 \%)(e)$.

report showed that low-syndiotactic-PMAA ( $r r \sim 60 \%)$ was hardly incorporated into 'regular' porous films ${ }^{40}$ we tried to compare with PMAA with an $r r=73 \%$ or greater, which is a similar $r r$ value to $s t$ PMAA in LbL preparation in current experiments. These results are shown in Table 2.

In the case of low stereoregularity st-PMAA, the polymer with a low molecular weight $\left(r r=73 \%, M_{\mathrm{n}}=18200\right)$ has a lower CE; $66 \pm 20 \%(n=4)$ (Table 2, run 1) than that of $s t$-PMAA-3 $(r r=78$, $M_{\mathrm{n}}=60800$ ) (Table 2, run 2), most likely due to the low Van der Waals forces secondary to the low molecular weight. Surprisingly, highly stereoregular $s t$-PMAA-4 $\left(r r=96 \%, M_{\mathrm{n}}=15200\right)$ was incorporated into the porous it-PMMA thin film with a CE of $>100 \%$, estimated to be $680 \%$ from QCM frequency shift, agains the extraction polymer (Table 2, run 3). This result indicates that the excess it-PMMA during the LbL process can be associated with the associating st-PMAA-3 $(r r=78 \%)$, which was loosely constructed, suggesting that the stereocomplex formation was increased by a rearrangement of the it-PMMA. In other words, structural changes in the porous it-PMMA thin film toward the ideal stereocomplex were found, accompanied by a rearrangement of the polymer conformation on the substrate that was different from the solid and liquid phases.

To examine such a strange incorporation behavior, the FT-IR spectra were analyzed (Figure 2). Compared with the stereocomplex film (Figure 2a), the peak intensity under $1700 \mathrm{~cm}^{-1}$ of porous it-PMMA film had decreased (Figure 2b). From this peak change, it is likely that the complete extraction of st-PMAA was achieved with $\mathrm{NaOH}$ solution. This result is consistent with the previous report. ${ }^{28}$ Corresponding with an increase in st-PMAA incorporated into the porous thin films, the peak intensity near $1715 \mathrm{~cm}^{-1}$ increased. This result was derived from the stereocomplexing st-PMAA (Figures $2 \mathrm{c}-\mathrm{e}$ ). In particular, Figure $2 \mathrm{c}$ indicates significant stereocomplex formation. If a large amount of st-PMAA physically adsorbed on the film surface, then the peak intensity at approximately $1650 \mathrm{~cm}^{-1}$ would have been measured in the FT-IR spectra. How- 


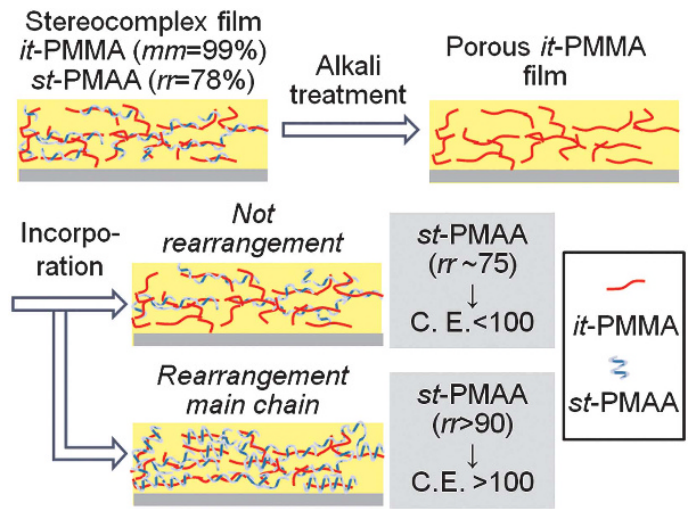

Figure 3 Schematic illustrations of molecular structure in stereocomplex films and porous isotactic-poly(methyl methacrylate) (it-PMMA) film which were dependent on the tacticity of syndiotactic-poly(methacrylic acid) (st-PMAA). CE, complex efficiency.

ever, the increased peak intensity is barely visible in this area (Figure 2c). Therefore, the detected polymer weight increase in QCM could show incorporation and stereocomplexation.

This result suggests that st-PMAA-4 $(r r=96 \%)$ can form a stereocomplex with the it-PMMA in the porous film-which was prepared with st-PMMA-3 $(r r=78 \%)$-more easily than normal physical absorption. A schematic illustration is shown in Figure 3 of the initial irregular stereocomplex due to the st-PMAA-3 $(r r=78 \%)$ that leads to an excess incorporation of st-PMAA-4 $(r r=96 \%)$

Table 2 shows the possibility of synthesizing polymers with high tacticity. Therefore, we synthesized PMAA within porous it-PMMA thin film. At first, we employed a QCM substrate to confirm the template polymerization with the irregular film (Figure 4). The progress of polymerization was monitored by the frequency shift of the QCM measurements and the FT-IR spectra. The polymerization efficiency was estimated at $37 \%$, which is lower than in the previous report, supporting the theory of random conformation of the polymer. 28,31

In addition, the FT-IR spectra showed the presence of polymerized PMAA in the porous films (Figure 5c). The spectrum of the thin film after polymerization showed a peak intensity increasing near $1715 \mathrm{~cm}^{-1}$. In this case, the peak intensity was so weak that the differential spectrum was investigated (shown in Figure $5 \mathrm{~d}$ ). The method of differential spectroscopy has been reported in a previous study. ${ }^{34}$ This result implied that the polymerization of MAA occurred in porous it-PMMA thin films.

We were also interested in the stereoregularity of the synthesized PMAA, but the quantity of synthesized polymer in the porous it-PMMA thin film on the QCM substrate was too small to characterize. Therefore, to investigate the stereoregularity of the PMAA synthesized in the porous it-PMMA thin film, a larger amount of stereocomplex was prepared for NMR analysis on a silica gel as a substrate from 100 steps of LbL. The stereocomplex film on the silica gel was verified by FT-IR spectroscopy, including the intensities dependent on the LbL steps (Figure 6). In Figure 6, the gradual increase of the $1735 \mathrm{~cm}^{-1}$ peak that suggests the formation of a stereocomplex and that the stereocomplex film was prepared on the silica gel surface sequentially.

Next, the it-PMMA porous thin film was prepared and examined. Template polymerization was achieved under the same polymerization conditions, temperature, and time as in the previous study. ${ }^{29,32,33}$

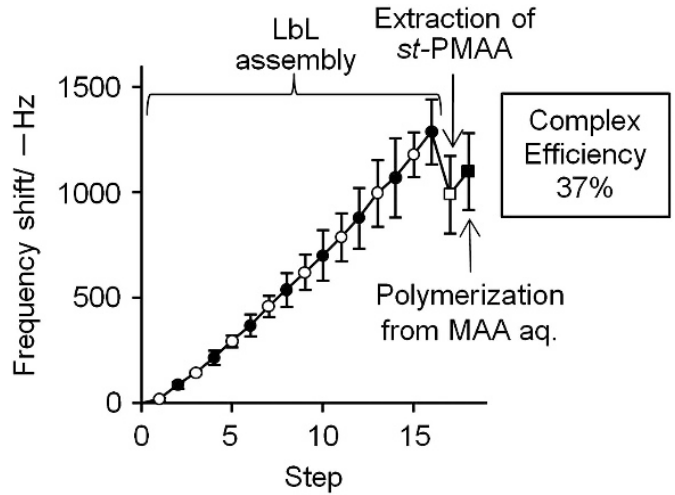

Figure 4 Quartz crystal microbalance (QCM) analysis of stepwise assembly from an isotactic-poly(methyl methacrylate) (it-PMMA-2) ( $m m=99 \%)$ acetonitrile solution (white circle) and a syndiotactic-poly(methacrylic acid) 3 (st-PMAA-3) $(r r=78 \%)$ solution of mixed acetonitrile/water $(4 / 6, v / v)$ solvent (black circle), extraction of st-PMAA with $10 \mathrm{~mm} \mathrm{NaOH}$ aq. (white square), and polymerization from MAA aq. in porous it-PMMA film (black square) $(n=3)$.

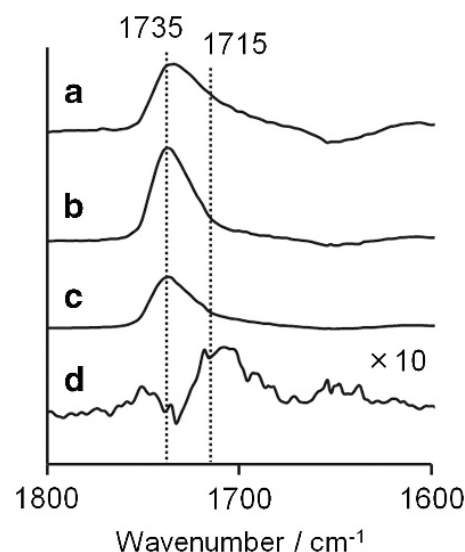

Figure $5 \mathrm{FT}-\mathrm{IR} /$ attenuated total reflection (ATR) spectra of isotacticpoly(methyl methacrylate) 2 (it-PMMA-2) $(m m=99 \%) /$ syndiotacticpoly(methacrylic acid) 3 (st-PMAA-3) ( $r r=78 \%)$ stereocomplex film (a), porous it-PMMA film (b), after polymerized film (c), and differential spectrum from (c) to (b) shown in (d).

After polymerization, the synthesized polymer was extracted with an alkali solution and was purified by reprecipitation. This extraction method was established in previous studies as well. ${ }^{29,32,33}$ The results of the template polymerization with ${ }^{1} \mathrm{H}$ NMR and SEC are shown in Table 3, and the typical ${ }^{1} \mathrm{H}$ NMR spectra are depicted in Figure 7.

The tacticity of the PMAA synthesized in porous it-PMMA thin films was close to that of the st-PMAA, which was employed for the initial LbL stereocomplex formation (Table 3, run 1). Interestingly, the tacticity of the synthesized PMAA showed a higher value than the PMAA, which was synthesized in solution (Table 3, run 1 and run 2). This result suggests that the tacticity of the synthesized PMAA is moderately controlled by the porous nano-space. Upon changing the solvent from water to a mixture of water and acetonitrile, the tacticity of the synthesized PMAA became closer to that of the extracted st-PMAA used with LbL assembly (Table 3, run 1 and run 3). However, the molecular weight changed dramatically and the molecular weight dispersion (PDI) increased, indicating that the solvent, which contributes to the solubility of the monomer, the 
radical initiator, and the synthesized polymer, influenced the template efficiency. Next, we investigated the effect of surface area by changing the amount of the silica gel (Table 3, run 7 and run 8). These PMMAs had tacticity and molecular weight values that were similar to the extracted st-PMAA. This similarity of tacticity and molecular weight value showed similar results to run 1 and run 2 in Table 3. In short, it was shown that the size of the porous it-PMMA thin film did not affect the product, and the irregular LbL film was mostly affected to synthesize PMAA.

Finally, we tried to reproduce the recycle reaction (Table 3, run 5 and run 6$).{ }^{33}$ Notably, the tacticities ( $r r=77 \%$ for run 5 and $78 \%$ for run 6 in Table 3) showed almost the same values, with slightly increased syndiotacticity. The details are still unclear, but this

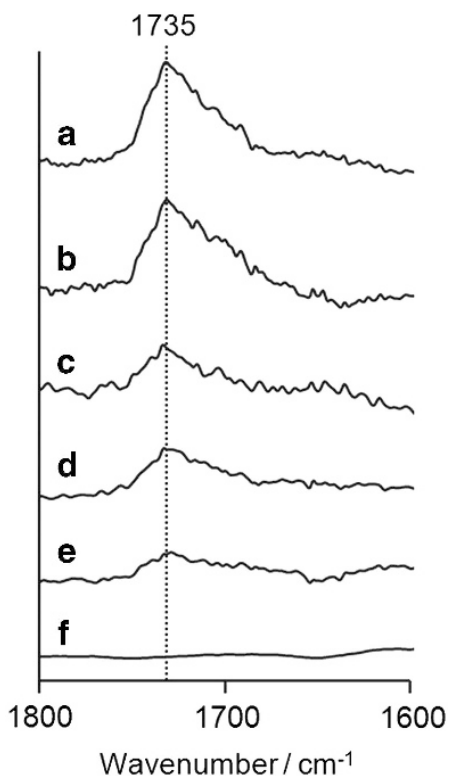

Figure $6 \mathrm{FT}-\mathrm{IR} /$ attenuated total reflection (ATR) differential spectra of isotactic-poly(methyl methacrylate) 2 (it-PMMA-2) $(\mathrm{mm}=99 \%) /$ syndiotacticpoly(methacrylic acid) 3 (st-PMAA-3) ( $r r=78 \%$ ) stereocomplex film on silica particles with 50 cycles (a), 40 cycles (b), 30 cycles (c), 20 cycles (d), 10 cycles (e), and silica particles (f). outcome could be due to a rearrangement of the it-PMMA in the irregular film, which approached a regular conformation through heating during the polymerization process.

\section{Conclusions}

We investigated the behavior of st-PMAA incorporation into irregular porous it-PMMA thin films, which were constructed with st-PMAA-3 $(r r=78 \%)$ and it-PMMA-2 $(m m=99 \%)$. Interestingly, we observed reforming behavior of the it-PMMA conformation in the porous films upon stereocomplexation with the higher st-PMAA-4 $(r r=96 \%)$. The presented results suggested that it-PMMA in porous films functions as an effective template for polymerization. However, this reforming ability was not observed for the polymerization reaction from monomer feeding. The stereocomplexation efficiency for polymerization might be different than that from polymer-polymer interactions. On the other hand, the irregular porous film, where the polymer structure was non-uniform,

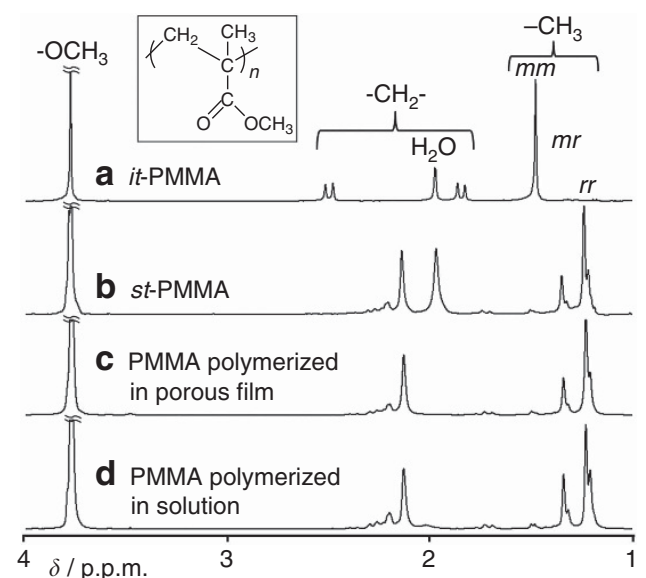

Figure $7{ }^{1} \mathrm{H}$ NMR spectra of isotactic-poly(methyl methacrylate) 2 (it PMMA-2) $(m m=99 \%)(a)$, syndiotactic-PMMA (from st-PMAA-3) $(r r=78 \%)$ (b), obtained poly (methacrylic acid) (PMAA) from radical polymerization in porous it-PMMA film (Table 3, run3) (c), and polymerized in acetonitrile/ $\mathrm{H}_{2} \mathrm{O}(4 / 6, v / v)$ solution (Table 3 , run 4) (d). These samples were measured in nitrobenzene- $d_{5}$ at $110^{\circ} \mathrm{C}(400 \mathrm{MHz})$. PMMA of (b), (c), and (d) were synthesized from PMAA with methylation.

Table 3 Results of polymerization ${ }^{a}$

\begin{tabular}{|c|c|c|c|c|c|c|c|c|c|}
\hline \multirow[t]{2}{*}{ Run } & \multirow[t]{2}{*}{ Polymer name } & \multirow[t]{2}{*}{ Polymerize solvent } & \multirow{2}{*}{$\begin{array}{l}\text { Scale } \\
m /\end{array}$} & \multirow{2}{*}{$\begin{array}{c}\text { Monomer } \\
\mathrm{mmol}\end{array}$} & \multicolumn{2}{|c|}{ Yield } & \multirow{2}{*}{$\begin{array}{l}\text { Tacticity }^{\mathrm{b}} \\
\text { mm:mr:rr }\end{array}$} & \multirow{2}{*}{$M_{n}^{c}$} & \multirow[t]{2}{*}{$P D I^{\mathrm{C}}$} \\
\hline & & & & & $m g$ & $\%$ & & & \\
\hline 1 & PMAA synthesized in porous film & $\mathrm{H}_{2} \mathrm{O}$ & 100 & 3.5 & 49 & $100^{d}$ & $3: 27: 70$ & 50800 & 1.44 \\
\hline 2 & PMAA synthesized in solution & & & & 53 & $75^{e}$ & $4: 31: 65$ & 65200 & 1.55 \\
\hline-- & PMAA synthesized in porous film & $\mathrm{MeCN}: \mathrm{H}_{2} \mathrm{O}(4: 6)$ & 100 & 3.5 & --- & $88^{d}$ & $2: 22: 76$ & 19700 & --- \\
\hline 4 & PMAA synthesized in solution & & & & 148 & $70^{e}$ & $3: 27: 70$ & 15700 & 3.30 \\
\hline 5 & Second recycle & & & & 52 & $87^{d}$ & $2: 21: 77$ & 27500 & 2.36 \\
\hline 6 & Third recycle & & & & 41 & $68^{d}$ & $2: 20: 78$ & 26000 & 2.84 \\
\hline-- & PMAA synthesized in porous film & $\mathrm{MeCN}: \mathrm{H}_{2} \mathrm{O}(4: 6)$ & 300 & 10.5 & 119 & $92^{d}$ & $3: 32: 65$ & 47500 & $\begin{aligned}--- \\
1.80\end{aligned}$ \\
\hline 8 & PMAA synthesized in solution & & & & 736 & $80^{e}$ & $5: 33: 62$ & 34200 & 2.20 \\
\hline
\end{tabular}

Abbreviations: it-PMMA, isotactic-poly(methyl methacrylate); PMAA, poly(methacrylic acid); st-PMAA-3, syndiotactic-poly(methacrylic acid) 3.

a Monomer concentration was $35 \mathrm{M}([\mathrm{M}] /[/]=1 / 20)$. Porous it-PMMA film were prepared from it-PMMA-2 (mm:mr:rr=99:1:0)/st-PMAA-3 (mm:mr:rr=1:21:78) stereocomplex film (Run 1-6) and it-PMMA-1 ( $m m: m r: r r=95: 4: 1) / s t-P M A A-2(m m: m r: r r=3: 24: 73)$ stereocomplex film (Run 7 and 8). PMAA were analyzed after methylation with diazomethane.

${ }^{b}$ Determined by ${ }^{1} \mathrm{H}$ NMR spectra in nitrobenzene- $d_{5}$ at $110^{\circ} \mathrm{C}(400 \mathrm{MHz})$.

cDetermined by SEC with PMMA standard in tetrahydrofuran (THF) at $40^{\circ} \mathrm{C}$

${ }^{d}$ Calculated by the equation: (synthesized PMAA)/(extracted st-PMAA from stereocomplex film) $\times 100$.

eThese values mean conversion which were calculated by the equation: (synthesized PMAA)/(total reactant) $\times 100$. 
can synthesize a low stereoregularity polymer with a value the same as the extracted polymer. In addition, strict control of the molecular weight and molecular weight distribution (PDI) was achieved using a low stereoregularity polymer. Furthermore, the present experiments revealed that polymerization in a porous film template can have narrow PDI values that are similar to the PDI values of free radical polymerization. Thus, it is important to use highly stereoregular polymers $(m m>90 \%$ and $r r>90 \%)$ to form the initial stereocomplex film to transfer the stereoregularity of the polymer of the porous thin film. These results show the difference between polymer-polymer interactions and monomer-polymer interactions and give essential insights into template polymerization systems and nano-space synthesis chemistry.

\section{CONFLICT OF INTEREST}

The authors declare no conflict of interest.

\section{ACKNOWLEDGEMENTS}

This work was partially supported by Sekisui-Kagaku Research-Aid Program on 'The Nature-Guided Materials Processing. This work was also supported in part by the MEXT project, 'Creating Hybrid Organs of the future' at Osaka University. We are also grateful to Drs T Kida, M Matsusaki, and T Akagi, Osaka University, for the fruitful discussions.

1 Szwarc, M. Replica polymerization. J. Polym. Sci. 13, 317-318 (1954).

2 Bamford, C. H. in Developments in Polymerisation (ed. Haward, R. N.) 215 (Applied Science Publishing, London, 1979).

3 Połowiński, S. in The Encyclopaedia of Advanced Materials (eds. Bloor, D., Brook, R. J., Flemings, M. C. \& Mahajan, S.) 2784 (Pergamon Press, Oxford, 1994).

4 Matuszewska, C. J. \& Połowiński, S. Template photopolymerization of methacrylic acid_II. Photopolymerization of methacrylic acid on poly(vinyl-pyrrolidone) in aqueous systems. Eur. Polym. J. 26, 549 (1990).

5 Takemoto, K., Akashi, M. \& Inaki, Y. Functional monomers and polymers. XIX. Copolymerization of vinyl monomers containing nucleic acid bases. J. Polym. Sci Polym. Chem. 12, 1861-1869 (1974).

6 Akashi, M., Inaki, Y. \& Takemoto, K. On the stereoregularity of vinyl polymers containing nucleic acid bases. Makromol. Chem. 178, 353-364 (1977).

7 Akashi, M., Kita, Y., Inaki, Y. \& Takemoto, K. Functional monomers and polymers. XXXXVI. A copolymerization study of methacryloyl-type monomers containing nucleic acid bases in chloroform solution. J. Polym. Sci Polym. Chem. 17, 301-312 (1979).

8 Akashi, M., Takada, H., Inaki, Y. \& Takemoto, K. Functional monomers and polymers. XXXXI. Template polymerization of methacryloyl-type monomers containing nucleic acid bases. J. Polym. Sci Polym. Chem. 17, 747-757 (1979).

9 Lo, P. K. \& Sleiman, H. F. Nucleobase-templated polymerization: copying the chain length and polydispersity of living polymers into conjugated polymers. J. Am. Chem. Soc. 131, 4182-4183 (2009).

10 Ida, S., Ouchi, M. \& Sawamoto, M. Designer template initiator for sequence regulated polymerization: systems design for substrate-selective metal-catalyzed radical addition and living radical polymerization. Macromol. Rapid Commun. 32, 209-214 (2011).

11 Nomura, S., Kyutoku, T., Shimomura, N., Kaneko, Y. \& Kadokawa, J. Preparation of inclusion complexes composed of amylose and biodegradable poly(glycolic acid-co-ecaprolactone) by vine-twining polymerization and their lipase-catalyzed hydrolysis behavior. Polym. J. 43, 971-977 (2011).

12 Fox, T. G., Garret, B. S., Goode, W. E., Grantch, S., Kincaid, J. F. \& Spell, A. Crystalline polymers of methyl methacrylate. J. Am. Chem. Soc. 80, 1768-1769 (1958).

13 Spěváček, J. \& Schneider, B. Aggregation of stereoregular poly(methyl methacrylates). Adv. Colloid Interface Sci 27, 81-150 (1987).

14 Bosscher, F., ten Brinke, G. \& Challa, G. Association of stereoregular poly(methy methacrylates). 6. Double-stranded helical structure of the stereocomplex of isotactic and syndiotactic poly(methyl methacrylate). Macromolecules 15, 1442-1444 (1982).

15 Schomaker, E. \& Challa, G. Complexation of stereoregular poly(methyl methacrylates). 14. The basic structure of the stereocomplex of isotactic and syndiotactic poly(methyl methacrylate). Macromolecules 22, 3337-3341 (1989).

16 Kumaki, J., Kawauchi, T., Okoshi, K., Kusanagi, H. \& Yashima, E. Supramolecular helical structure of the stereocomplex composed of complementary isotactic and syndiotactic poly(methyl methacrylate)s as revealed by atomic force microscopy. Angew. Chem. Int. Edn. Engl. 46, 5348-5351 (2007).
17 Buter, R., Tan, Y. Y. \& Challa, G. Radical polymerization of methyl methacrylate in the presence of isotactic poly(methy1 methacrylate). J. Polym. Sci. A Polym. Chem. 10, 1031-1049 (1972).

18 Buter, R., Tan, Y. Y. \& Challa, G. Radical polymerization of methyl methacrylate in the presence of stereoregular poly (methyl methacrylate). II. Syndiotactic PMMA as Matrix. J. Polym. Sci. A Polym. Chem. 11, 1003-1011 (1973).

19 Buter, R., Tan, Y. Y. \& Challa, G. Radical polymerization of methyl methacrylate in the presence of stereoregular poly(methyl methacrylate). III. Influence of temperature. J. Polym. Sci. A Polym. Chem. 11, 1013-1024 (1973).

20 Buter, R., Tan, Y. Y. \& Challa, G. Radical polymerization of methyl methacrylate in the presence of stereoregular poly (methyl methacrylate). IV. Influence of solvent type. J. Polym. Sci. A Polym. Chem. 11, 2975-2989 (1973).

21 Gons, J., Vorenkamp, J. \& Challa, G. Radical polymerization of methyl methacrylate in the presence of stereoregular polymmethy1 methacrylate). V. Kinetics of initial template polymerization. J. Polym. Sci. A Polym. Chem. 13, 1699-1709 (1975).

22 Gons, J., Slagter, O. W. \& Challa, G. Radical polymerization of methyl methacrylate in the presence of stereoregular poly(methy1 methacrylate). VI. Kinetic template effects at higher conversion. J. Polym. Sci. A Polym. Chem. 15, 771-779 (1977).

23 Gons, J., Vorenkamp, J. E. \& Challa, G. Radical polymerization of methyl methacrylate in the presence of isotactic poly(methy 1 metacrylate).VII. Determination of the rate constants for template polymerization. J. Polym. Sci. A Polym. Chem. 15, 3031-3038 (1977).

24 Gons, J., Straatman, P. J. L. \& Challa, G. Radical polymerization of methyl methacrylate in the presence of isotactic poly(methyl methacrylate). VIII. Influence of template concentration. J. Polym. Sci. A Polym. Chem. 16, 427-434 (1978).

25 Yau, H. \& Stupp, S. I. Solid matrix polymerization and stereoisomeric complexes of poly(methy1 methacrylate. J. Polym. Sci Polym. Chem. 23, 813-828 (1985).

26 Nodono, M., Makino, T. \& Nishida, K. Studies on random coil-helix transformation of syndiotactic poly(methyl methacrylate) and stereospecific template polymerization of methyl methacrylate in the presence of syndiotactic poly(methyl methacrylate). React. Funct. Polym. 57, 157-161 (2003).

27 Serizawa, T., Hamada, K., Kitayama, T., Katsukawa, K., Hatada, K. \& Akashi, M. Stepwise assembly of isotactic poly(methyl methacrylate) and syndiotactic poly (methacrylic acid) on a substrate. Langmuir 16, 7112-7115 (2000).

28 Serizawa, T., Hamada, K., Kitayama, T. \& Akashi, M. Recognition of stereoregular polymers by using structurally regulated ultrathin polymer films. Angew. Chem. Int. Edn. Engl. 42, 1118-1121 (2003).

29 Serizawa, T., Hamada, K. \& Akashi, M. Polymerization within a molecular-scale stereoregular template. Nature 429, 52-55 (2004).

30 Ajiro, H., Hongo, C., Maegawa, M., Kamei, D., Sasaki, S., Ogawa, H., Masunaga, H., Takemoto, Y., Horie, K. \& Akashi, M. Structural nanospace feature and substrate contribution to maintaining stable porosity of polymer chain in layer-by-layer assembled isotactic poly(methyl methacrylate) films. Macromolecules 45, 7660-7663 (2012).

31 Ajiro, H., Maegawa, M. \& Akashi, M. Thermal stability of porous it-PMMA thin film obtained by the extraction of st-PMAA from it-PMMA/st-PMAA stereocomplex with layer-by-layer assembly on a substrate. J. Polym. Sci. A Polym. Chem. 48, 3265-3270 (2010).

32 Hamada, K., Serizawa, T. \& Akashi, M. Template polymerization using artificial double strands. Macromolecules 38, 6759-6761 (2005).

33 Ajiro, H., Kamei, D. \& Akashi, M. Macroporous silicagel substrate for stereoregular template polymerization of methacrylic acid using stereocomplex assembled thin films. Polym. J. 41, 90-93 (2009).

34 Ajiro, H., Kamei, D. \& Akashi, M. Mechanistic studies on template polymerization in porous isotactic poly(methyl methacrylate) thin films by radical polymerization and post-polymerization of methacrylate derivatives. Macromolecules 42, 3019-3025 (2009).

35 Ajiro, H., Maegawa, M. \& Akashi, M. Nanospace preparation by crosslinking helical syndiotactic-poly(methacrylic acid) in acetonitrile/water after stereocomplexation. J. Polym. Sci. A Polym. Chem. 50, 1469-1476 (2012).

36 Hatada, K., Ute, K., Tanaka, K., Kitayama, T. \& Okamoto, Y. Preparation of highly isotactic poly(methyl methacrylate) of low polydispersity. Polym. J. 17, 977-980 (1985).

37 Kitayama, T., He, S., Hironaka, Y., lijima, T. \& Hatada, K. Preparation of highly stereoregular poly(methacrylic acid) by stereospecific anionic polymerization of trimethylsilyl methacrylate. Polym. J. 27, 314-318 (1995).

38 Serizawa, T., Hamada, K., Kitayama, T., Fujimoto, N., Hatada, K. \& Akashi, M. Stepwise tereocomplex assembly of stereoregular poly(methyl methacrylate)s on a substrate. J. Am. Chem. Soc. 122, 1891-1899 (2000).

39 Sauerbrey, G. The use of quarts oscillators for weighing thin layers and for microweighing. Z. Phys. 155, 206-222 (1959).

40 Kamei, D., Ajiro, H. \& Akashi, M. Specific recognition of syndiotactic poly(methacrylic acid) in porous isotactic poly(methyl methacrylate) thin films based on the effects of stereoregularity, temperature, and solvent. J. Polym. Sci. A Polym. Chem. 48, 3651-3657 (2010). 